\title{
Max Born
}

\section{December 1882 5 January 1970}

The time and place of a man's life deeply mark his personal development and that of his work. Max Born was a little younger than Albert Einstein, Lise Meitner, Otto Hahn and Max von Laue, of the same age as James Franck, and only slightly older than Pieter Debye and Niels Bohr. To this generation, when it was 20 to 25 years of age, physics assigned great tasks. Quantum theory was only in its infancy and the theory of relativity was being born. Luck also dictated that Born's father was a university professor and a respected scientist, so that Born grew up in an intellectually inspiring and challenging atmosphere, free from economic want. Consequently, it was possible for him to study a broad range of subjects at several universities. Soon, however, he concentrated his interests on mathematics and discovered that Göttingen had most to offer.

Born came to this university in 1906 during the time of the shining triumvirat Felix Klein, David Hilbert and Hermann Minkowski - all three of whom were vividly interested in physics. Born's Ph.D. thesis (1908) concerned one of the problems under investigation during this period, but of more interest to him was the theory of relativity which was being formulated. Soon he contributed publications himself on this subject and in a short time he became docent in mathematical physics in Göttingen.

The second phase in Born's scientific development can be characterized by a research programme whose subject was the understanding of the mechanical, thermal, electrical and optical properties of solids on the basis of their atomic composition. The theory of the specific heat of crystals, elaborated together with Theodor von Kármán was the first explicit result of this programme and a book was published in 1915 closing the first stage of the research. However, the programme was later continued and led to a comprehensive article in the "Encyclopaedia of Mathematical Sciences" in 1922. Up to the present day Born's "Ansätze" are being developed further. His analysis of the properties of ionic crystals was, at the time, particularly far-reaching and inspiring.

In 1915 Born became a professor in Berlin, where Einstein was elaborating on the theory of general relativity and Planck on quantum theory. Born's participation in these discussions was, however, limited because of the first World War. In 1919 he became a professor in Frankfurt (Main), where Stern and Gerlach demonstrated the directional quantization of an atom in a magnetic field. In 1921 he returned to Göttingen, at the dawn of a particularly happy time for physics in Göttingen. As a condition for his appointment, Born had posed that simultaneously James Franck be called as a professor to the same university, a condition which was accepted.

Initially, Born occupied his fastgrowing team of pupils with special problems in the theory of crystal lattices. But now began the third phase of his scientific work, which was devoted to quantum mechanics. His critical mind was not satisfied with the interpretations of the theory at that time: Bohr's intuitive grasp of the direction in which classical mechanics had to be modified, and Sommerfeld's insistence upon the validity of the phase integral. Where did the old theory fail? This was demonstrated in a calculation of the helium spectrum, carried through in 1923 with Heisenberg. How far did the theory go? This was staked out in a lecture series during the winter term 1923/24 and in a book which appeared in 1924. In what way was the old theory to be modified? This was explored through calculations in Copenhagen and Göttingen.

Born succeeded in presenting Heisenberg's solution of 1925 in an illuminating mathematical form; the fundamental relation $i(p q-q p)=h / 2 \pi$ can rightly be called Born's equation. Through the collective effort of three men: Born, Heisenberg and Jordan the foundations of quantum mechanics were constructed. Immediately after the appearance of Schroedinger's first paper, Born saw the possibility of successfully treating the quantum theory of aperiodic phenomena. In an

\section{F. Hund Göttingen}

Translated from the German by L. Jansen article on collision processes he interpreted the quantity $\Psi * \Psi$ as the probability of a physical state of the system in this manner he paved the way towards an understanding of the mathematical formalism.

Born's years in Göttingen were marked by close friendship and collaboration with Franck, by a growing circle of talented pupils and of other prominent physicists who for shorter and longer periods were associated with him. To these belonged (in approximate chronological order): Pauli, Fermi, Heisenberg, Jordan, Condon, Frenkel, Nordheim, Heitler, Mulliken Dirac, Rosenfeld, Fock, GöppertMayer, Oppenheimer, Delbrück, von Neumann, Flügge. In 1933 these happy times came to an end, and Born left the place of his work which had become so dear to him.

After a brief intermezzo in India and in Cambridge (UK), Born received the Tait Professorship in Edinburgh. His sphere of activity became more limited than in Göttingen, but in Edinburgh also Born found good collaborators. His attempts at a quantum field theory, though premature at the time, proved valuable as model considerations. Articles on melting (about 1937) and on the theory of liquids, initiated with H.S. Green (1946), opened a new field of research. But time and time again Born returned to his theory of lattices, polishing and refining many of its aspects.

After his retirement (1953) Born terminated his activities as a physicist. He returned to Germany and, together with his wife, he devoted himself to a new important task. He knew of the consequences which the unbridled application of scientific knowledge can have. In particular, he knew that the exploitation of nuclear forces, with its millionfold increase in energy concentration, constitutes a completely new situation for mankind and not simply a further development of prior possibilities.

His efforts, in both written and spoken word, have helped to raise the new situation and its cataclysmic dangers into the public conscience. 


\section{Criteria for Sponsorship of Conferences by the EPS}

The following terms for sponsorship of Conferences were proposed by the Conference Committee and accepted by the Council.

\section{Scientific Value}

a) There should be a clearly demonstrated need for the proposed conference, i.e. new and important advances since the last conference of a similar type took place.

b) The invited speakers and the papers accepted for discussion should be of high calibre.

c) Acceptance of communications should be based on some sort of refereeing system which ensures a level comparable with that of papers in the regular journals.

\section{International Character}

a) There should be an international committee to advise on the scientific programme and on the names of the lecturers. With the agreement of the International Advisory Committee the detailed organization and the refereeing of communications may be in the hands of a local organizing committee. The refereeing of communications and the editing of the published proceedings should, however, have an international element.

b) Participation should be genuinely international, both as regards participants and invited speakers. The aim should be that at least one half of the invited speakers, rapporteurs and discussion leaders should come from outside the host country.

c) Attendance must be independent of nationality or citizenship. The International Advisory Committee should in addition ensure an appropriate geographical distribution of participants. d) The EPS will only sponsor conferences on the understanding that for the venue chosen there will be no restriction on the attendance of members from anywhere (By-laws, Rule 32).

e) EPS sponsorship relates to meetings with a predominant European character.

\section{Organization}

Sponsorship is granted by the Executive Committee of the European Physical Society on the recommendation of the Conference Committee.

Requests for sponsorship accompanied by full information should whenever possible be received by the EPS Secretariat in Geneva twelve months prior to the date of the conference concerned. Requests should be addressed to:

\section{Conference Committee,}

European Physical Society,

P.O. Box, CH-1227 Carouge Geneva, Switzerland.

\section{Classified Advertisements}

\section{University of Groningen (Netherlands), Chair of Experimental Nuclear Physics}

Applications are invited for the position of full professor in experimental nuclear physics, at a gross-salary of Hfl. 58.000.- per annum. The professor, to be appointed in 1970, will be encharged with planning and execution of experiments in nuclear physics with the particle beams from the new 280 $\mathrm{cm}$ A.V.F. cyclotron: protons and deuterons up to $70 \mathrm{MeV}$; alpha-particles up to $140 \mathrm{MeV}$, and heavier ions. $\mathrm{He}$ is also expected to participate in the general guidance of the Cyclotron Institute, and in the teaching of nuclear physics (familiarity with the Dutch lan- guage is not necessary). Applications and enquiries (which will be treated in confidence) will be welcomed from persons with considerable experience in nuclear physics. They should be addressed to the Office of the Faculty of Science, University of Groningen, Oude Kijk in 't Jatstraat 28, Groningen, Netherlands. Suggestions of possible suitable candidates, with full references, will also be appreciated.

\section{Plasma Physics Glossary}

A Plasma Physics Glossary (Part 1) has been published by the Terminology Bureau of the Commission of the European Communities, Brussels, Belgium, Corthenberg 1/92.

It is intended as a. working document for Division iX/C4 of the Commission of the European Communities, but should also become a useful glossary for various plasma physics laboratories and research workers all over the world. Part I contains alphabetical lists in English, German, French, Italian and Dutch in the field of controlled thermonuclear fusion and associated plasma physical problems.

Copies are available cost-free to any specialist in the field. All requests should be addressed to Dr. H. Kowalski, Head of the Terminology Bureau of the Commission of the European Communities, rue de la Loi 200, 1040 Brussels, Belgium.

\section{Free University of Brussels (Belgium)}

Applications are invited for the position of professor or lecturer in ASTRONOMY from 1 October 1970.

Applications with curriculum vitae and publications should be sent by 12 April 1970, to the Rector of the "VRIJE UNIVERSITEIT BRUSSEL", Adolphe Buyllaan 105, B-1050 Brussels. 